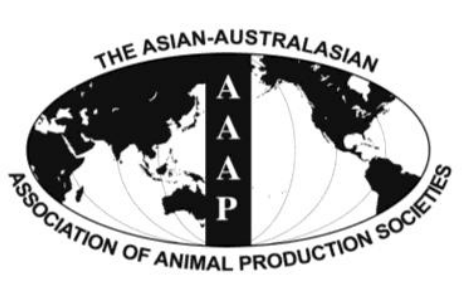

Open Access

Asian Australas. J. Anim. Sci.

Vol. 27 , No. 7 : $981-989$ July 2014

http://dx.doi.org/10.5713/ajas.2013.13449

www.ajas.info

pISSN 1011-2367 elSSN 1976-5517

\title{
Effects of Functional Oils on Coccidiosis and Apparent Metabolizable Energy in Broiler Chickens
}

\author{
A. E. Murakami*, C. Eyng, and J. Torrent ${ }^{1}$ \\ Department of Animal Science, Universidade Estadual de Maringá, Maringá, PR 87020-900, Brazil
}

\begin{abstract}
The objective of the present study was to investigate the effects of a mixture of functional oils (Essential, Oligo Basics Agroind. Ltda) on performance response of chickens challenged with coccidiosis and the determination of apparent metabolizable energy (AME), nitrogen-corrected apparent metabolizable energy (AMEn), the coefficients of protein and ether extract digestibility and intestinal morphology of broilers fed with diets containing Essential. In Exp. 1, a completely randomized design (CRD) was used, with one control diet without Essential inclusion with coccidiosis (Eimeria acervulina, Eimeria maxima, and Eimeria tenella) challenged birds and two different inclusion rates of Essential $(1.5 \mathrm{~kg} / \mathrm{ton}$ and $2 \mathrm{~kg} / \mathrm{ton})$ with coccidiosis-challenged and non-challenged birds for each inclusion rate, using 10 replicates and 50 birds per experimental unit. After $7 \mathrm{~d}$ of coccidiosis challenge, the livability was approximately $10 \%$ lower $(\mathrm{p}<0.05)$ for the control group. Intestinal lesion scores were lower $(\mathrm{p}<0.05)$ in the anterior intestine and the cecum for the chickens supplemented. Feed efficiency and growth rate were improved in birds supplemented with Essential $(p<0.05)$ before the coccidiosis challenge and during the first $7 \mathrm{~d}$ post infection. In Exp. 2, a CRD was used, with one control diet without Essential inclusion and one diet with inclusion of Essential $(1.5 \mathrm{~kg} / \mathrm{ton})$, using nine replications and 33 chicks per pen. The diets with Essential yielded approximately 4\% higher $\operatorname{AME}(\mathrm{p}=0.003)$ and $\mathrm{AME}_{\mathrm{n}}(\mathrm{p}=0.001)$. Essential supplementation increased villus height in the jejunum on $d 14(p<0.05)$. Villus height:crypt depth ratio for the supplemented birds was larger $(p<0.05)$ in the jejunum on $d 7$, larger $(\mathrm{p}<0.05)$ in the jejunum and ileum on $\mathrm{d} 14$. In conclusion, these functional oils improved the energy utilization and the livability and decreased lesions caused by coccidiosis in supplemented birds. (Key Words: Anticoccidial Activity, Apparent Metabolizable Energy, Functional Oils, Growth Enhancer)
\end{abstract}

\section{INTRODUCTION}

Coccidiosis represents a very serious challenge to the broiler industry. Although ionophores are the most common compounds used to prevent infection, continuous use of these molecules has created resistance and new molecules have not been developed. New regulations and increased consumer interest in animal products developed without the use of antibiotics have led to the search for products that are considered natural by the consumer.

Functional oils are defined as those oils that have an action beyond the nutritional value. Castor oil is one of

\footnotetext{
* Corresponding Author: A. E. Murakami. Tel: +55-44-32618942, E-mail: aemurakami@uem.br

${ }^{1}$ Oligo Basics USA LLC, Wilmington, DE 19809, USA.

Submitted Jul. 26, 2013; Revised Oct. 19, 2013; Accepted Jan. 25, 2014
}

these functional oils and which comes from Ricinus communis. The pharmacologically active molecule in the oil is ricinoleic acid, which is approximately $90 \%$ of the entire fatty acid chain composition. Besides its laxative effects that can prevent its use, ricinoleic acid has been shown to have antimicrobial (Novak et al., 1961) and antiinflammatory actions (Vieira et al., 2001), which makes this acid an ideal candidate for preventing intestinal problems.

The shell of the cashew nut (Anacardium occidentale L.) contains an alkylphenolic oil which is internationally known as "cashew nut shell liquid" (CNSL) and constitutes nearly $25 \%$ of the total weight of the nut. This oil is mainly composed of anacardic acid (3-n-pentadecylsalicylic acid), cardanol (3-n-pentadecylphenol), cardol (5-npentadecylresorcinol), and methylcardol (2-methyl-5-npentadecylresorcinol). The biologic activities of the CNSL components have attracted considerable attention in the 
areas of molluscicidal activity (Kubo et al., 1986), antitumor activity (Itokawa et al., 1989) and antimicrobial activity (Kubo et al., 2003). The synergistic antimicrobial property of CNSL with other antibiotics is of special interest (Muroi and Kubo, 1996).

As CNSL may increase the antimicrobial activity of castor oil allowing a decrease in the castor oil dosage to non-laxative levels, a mixture of CNSL and castor oil was developed for oral use as commercial product called "Essential" (Essential, US Patent Nº. 8,377,485 B2: Oligo Basics Agroind. Ltda., Rua Sérgio Gasparetto 503, Cascavel, PR-CEP, Brazil).

Based on the data that anacardic acids work as ionophores in the mitochondria (Toyomizu et al., 1999) and that ricinoleic acid has also been shown to work as an ionophore (Maenz and Forsyth, 1982), it was hypothesized that Essential would have anticoccidial activities. Also, as ricinoleic acid and CNSL affect different enzyme activities, the effects of Essential on apparent metabolizable energy (AME) were also investigated.

The objective of the present study was to investigate the efficacy of Essential on performance response of chickens challenged with coccidiosis and the determination of AME, nitrogen-corrected apparent metabolizable energy $\left(\mathrm{AME}_{\mathrm{n}}\right)$, the coefficients of protein and ether extract digestibility and intestinal morphology of broilers fed with diets containing Essential.

\section{MATERIAL AND METHODS}

Two experiments were conducted in the experimental farm of the State University of Maringá, State of Paraná, Brazil (Universidade Estadual de Maringá, Paraná) with the approval of the Institutional Animal Care and Use Committee, which oversees research with animal subjects at university facilities.

\section{Exp. 1, coccidiosis inoculation experiment}

Animals, experimental design and dietary treatments: A total of 3,000 one-d-old male (Cobb-500) broilers were obtained from a commercial hatchery. The experimental design included broilers randomly assigned to five treatments. The treatment groups consisted of: control diet without Essential inclusion in coccidiosis-challenged birds; Essential supplementation at $1.5 \mathrm{~kg} / \mathrm{ton}$ in coccidiosischallenged birds; Essential supplementation at $1.5 \mathrm{~kg} / \mathrm{ton}$ in coccidiosis non-challenged birds; Essential supplementation at $2.0 \mathrm{~kg} / \mathrm{ton}$ in coccidiosis-challenged birds and Essential supplementation at $2.0 \mathrm{~kg} / \mathrm{ton}$ in coccidiosis non-challenged birds.

The experimental units were repeated 10 times with 50 birds each. The experimental diets, based on corn and soybean meal, were formulated to meet Brazilian nutrient requirements for broiler chickens (Rostagno et al., 2005) for the 1 to 21 -d-old and 22 to 42 -d-old age groups (Table 1).

Infective material: The experiment was carried out with field strains of Eimeria maxima, Eimeria acervulina, and Eimeria tenella. Oocysts were harvested from the feces of birds from bird houses with coccidiosis field outbreaks. The oocysts were sporulated and kept in a $2 \%$ potassium

Table 1. Percent and calculated composition of experimental diets for the coccidiosis inoculation experiment (Exp. 1)

\begin{tabular}{lcc}
\hline Item & $\begin{array}{c}\text { Initial } \\
(1 \text { to } 21 \mathrm{~d})\end{array}$ & $\begin{array}{c}\text { Grower } \\
(22 \text { to } 42 \mathrm{~d})\end{array}$ \\
\hline Ingredients (\%) & & \\
Corn & 52.39 & 55.26 \\
Soybean meal, 45\% & 39.00 & 35.00 \\
Soybean oil & 4.50 & 5.80 \\
Limestone & 1.00 & 1.00 \\
Dicalcium Phosphate & 1.90 & 1.80 \\
NaCl & 0.300 & 0.300 \\
Sodium Bicarbonate & 0.250 & 0.200 \\
L-Lys HCl 78.5\% & 0.150 & 0.150 \\
DL-Met, 98\% & 0.300 & 0.280 \\
L-Thr, 98\% & 0.050 & 0.050 \\
BHT & 0.010 & 0.010 \\
Supplement minerals & 0.150 & 0.150 \\
$\quad$ and vitamins 1,2 & & \\
Total & 100.00 & 100.00 \\
Calculated composition & & \\
ME (kcal/kg) & 3,091 & 3,212 \\
CP (g/kg) & 220.9 & 205.0 \\
Calcium (g/kg) & 9.44 & 9.11 \\
Available phosphorus $(\mathrm{g} / \mathrm{kg})$ & 4.40 & 4.00 \\
Digestible Met+cys $(\mathrm{g} / \mathrm{kg})$ & 9.17 & 8.60 \\
Digestible Lys $(\mathrm{g} / \mathrm{kg})$ & 12.11 & 11.14 \\
Digestible Thr $(\mathrm{g} / \mathrm{kg})$ & 7.81 & 7.26 \\
\hline
\end{tabular}

BHT, hydroxy butyl toluene; ME, metabolizable energy; CP, crude protein.

${ }^{1}$ Vitamin supplement, initial (content per kg of diet): vitamin A (retinyl acetate) 11,667 IU; vitamin $\mathrm{D}_{3}$ (cholecalciferol) 2,333 IU; vitamin $\mathrm{E}$ (DL- $\alpha$-tocopheryl acetate) $35 \mathrm{IU}$; vitamin $\mathrm{K}_{3}$ (menadione dimethylpyrimidinol) $1.73 \mathrm{IU}$; vitamin $\mathrm{B}_{1}$ (thiamine mononitrate) 1.63 $\mathrm{mg}$; vitamin $\mathrm{B}_{2}$ (riboflavin) $5.33 \mathrm{mg}$; vitamin $\mathrm{B}_{12}$ (cyanocobalamin) 0.02 $\mathrm{mg}$; niacin (niacinamide) $35.93 \mathrm{mg}$; calcium pantothenate $12.67 \mathrm{mg}$; folic acid $0.80 \mathrm{mg}$; D-biotin $0.10 \mathrm{mg}$. Mineral supplement (content per $\mathrm{kg}$ of diet): $\mathrm{Fe}$ (iron sulfate monohydrate) $50.40 \mathrm{mg} ; \mathrm{Cu}$ (cooper sulfate pentahydrate) $12.29 \mathrm{mg}$; I (calcium iodate) $0.99 \mathrm{mg}$; Zn (zinc oxide) $50.40 \mathrm{mg}$; Mn (manganous oxide) $60 \mathrm{mg}$; Se (sodium selenite) $0.24 \mathrm{mg}$; Co (cobalt sulfate) $0.20 \mathrm{mg}$.

${ }^{2}$ Vitamin supplement, grower (content per kg of diet): vitamin A (retinyl acetate) 9,000 IU; vitamin $\mathrm{D}_{3}$ (cholecalciferol) 1,800 IU; vitamin $\mathrm{E}$ (DL$\alpha$-tocopheryl acetate) $28 \quad \mathrm{IU} ; \quad$ vitamin $\mathrm{K}_{3} \quad$ (menadione dimethylpyrimidinol) $1.67 \mathrm{IU}$; vitamin $\mathrm{B}_{1}$ (thiamine mononitrate) 1.20 $\mathrm{mg}$; vitamin $\mathrm{B}_{2}$ (riboflavin) $4 \mathrm{mg}$; vitamin $\mathrm{B}_{12}$ (cyanocobalamin) 0.01 $\mathrm{mg}$; niacin (niacinamide) $28 \mathrm{mg}$; calcium pantothenate $10 \mathrm{mg}$; folic acid $0.56 \mathrm{mg}$; D-biotin $0.06 \mathrm{mg}$. Mineral supplement (content per kg of diet): $\mathrm{Fe}$ (iron sulfate monohydrate) $52 \mathrm{mg}$; $\mathrm{Cu}$ (cooper sulfate pentahydrate) $12 \mathrm{mg}$; I (calcium iodate) $1 \mathrm{mg}$; Zn (zinc oxide) $52 \mathrm{mg}$; Mn (manganous oxide) $60 \mathrm{mg}$; Se (sodium selenite) $0.30 \mathrm{mg}$; Co (cobalt sulfate) $0.20 \mathrm{mg}$. 
Table 2. Percent and calculated composition of experimental diets for the metabolizability experiment (Exp. 2)

\begin{tabular}{|c|c|c|c|}
\hline Item & $\begin{array}{c}\text { Initial } \\
\text { (1 to } 14 \mathrm{~d})\end{array}$ & $\begin{array}{l}\text { Grower } \\
\text { (15 to } 28 \mathrm{~d})\end{array}$ & $\begin{array}{l}\text { Finisher } \\
\text { (29 to } 42 \text { d) }\end{array}$ \\
\hline \multicolumn{4}{|l|}{ Ingredients } \\
\hline Corn & 59.56 & 62.22 & 64.79 \\
\hline Soybean meal, $45 \%$ & 34.79 & 31.08 & 28.14 \\
\hline Soybean oil & 1.42 & 2.83 & 3.45 \\
\hline Limestone & 0.97 & 0.79 & 0.77 \\
\hline Dicalcium phosphate & 1.83 & 1.74 & 1.59 \\
\hline $\mathrm{NaCl}$ & 0.40 & 0.40 & 0.40 \\
\hline L-Lys $\mathrm{HCl}, 78.5 \%$ & 0.322 & 0.307 & 0.260 \\
\hline DL-Met, $98 \%$ & 0.303 & 0.255 & 0.229 \\
\hline L-Thr, $98 \%$ & 0.112 & 0.101 & 0.067 \\
\hline Supplement minerals and vitamins $s^{1,2}$ & 0.150 & 0.150 & 0.150 \\
\hline Inert carrier/Essential $^{3}$ & 0.150 & 0.150 & 0.150 \\
\hline Total & 100.00 & 100.00 & 100.00 \\
\hline \multicolumn{4}{|l|}{ Calculated composition } \\
\hline $\mathrm{ME}(\mathrm{kcal} / \mathrm{kg})$ & 2,980 & 3,050 & 3,125 \\
\hline $\mathrm{CP}(\mathrm{g} / \mathrm{kg})$ & 215.0 & 200.0 & 188.0 \\
\hline Calcium $(\mathrm{g} / \mathrm{kg})$ & 9.50 & 8.50 & 8.00 \\
\hline Available phosphorus (g/kg) & 4.50 & 4.30 & 4.00 \\
\hline Digestible Met+cys (g/kg) & 8.80 & 8.00 & 7.50 \\
\hline Digestible Lys (g/kg) & 12.50 & 11.50 & 10.45 \\
\hline Digestible Thr (g/kg) & 8.10 & 7.50 & 6.80 \\
\hline Digestible $\operatorname{Trp}(\mathrm{g} / \mathrm{kg})$ & 2.36 & 2.16 & 1.99 \\
\hline
\end{tabular}

ME, metabolizable energy; CP, crude protein.

${ }^{1}$ Vitamin supplement, initial (content per kg of diet): vitamin A (retinyl acetate) 11,667 IU; vitamin $\mathrm{D}_{3}$ (cholecalciferol) 2,333 IU; vitamin E (DL- $\alpha$ tocopheryl acetate) $35 \mathrm{IU}$; vitamin $\mathrm{K}_{3}$ (menadione dimethylpyrimidinol) $1.73 \mathrm{IU}$; vitamin $\mathrm{B}_{1}$ (thiamine mononitrate) $1.63 \mathrm{mg}$; vitamin $\mathrm{B}_{2}$ (riboflavin) $5.33 \mathrm{mg}$; vitamin $\mathrm{B}_{12}$ (cyanocobalamin) $0.02 \mathrm{mg}$; niacin (niacinamide) $35.93 \mathrm{mg}$; calcium pantothenate $12.67 \mathrm{mg}$; folic acid $0.80 \mathrm{mg}$; D-biotin $0.10 \mathrm{mg}$. Mineral supplement (content per $\mathrm{kg}$ of diet): Fe (iron sulfate monohydrate) $50.40 \mathrm{mg}$; Cu (cooper sulfate pentahydrate) $12.29 \mathrm{mg}$; I (calcium iodate) $0.99 \mathrm{mg}$; Zn (zinc oxide) $50.40 \mathrm{mg}$; Mn (manganous oxide) $60 \mathrm{mg}$; Se (sodium selenite) $0.24 \mathrm{mg}$; Co (cobalt sulfate) $0.20 \mathrm{mg}$.

${ }^{2}$ Vitamin supplement, grower and finisher (content per kg of diet): vitamin A (retinyl acetate) 9,000 IU; vitamin $\mathrm{D}_{3}$ (cholecalciferol) $1,800 \mathrm{IU}$; vitamin $\mathrm{E}$ (DL- $\alpha$-tocopheryl acetate) $28 \mathrm{IU}$; vitamin $\mathrm{K}_{3}$ (menadione dimethylpyrimidinol) $1.67 \mathrm{IU}$; vitamin $\mathrm{B}_{1}$ (thiamine mononitrate) $1.20 \mathrm{mg}$; vitamin $\mathrm{B}_{2}$ (riboflavin) $4 \mathrm{mg}$; vitamin $\mathrm{B}_{12}$ (cyanocobalamin) $0.01 \mathrm{mg}$; niacin (niacinamide) $28 \mathrm{mg}$; calcium pantothenate $10 \mathrm{mg}$; folic acid $0.56 \mathrm{mg}$; D-biotin 0.06 $\mathrm{mg}$. Mineral supplement (content per kg of diet): Fe (iron sulfate monohydrate) $52 \mathrm{mg}$; Cu (cooper sulfate pentahydrate) $12 \mathrm{mg}$; I (calcium iodate) $1 \mathrm{mg}$; $\mathrm{Zn}$ (zinc oxide) $52 \mathrm{mg}$; Mn (manganous oxide) $60 \mathrm{mg}$; Se (sodium selenite) $0.30 \mathrm{mg}$; Co (cobalt sulfate) $0.20 \mathrm{mg}$.

${ }^{3}$ Essential would take the place of the inert carrier in the treatments supplemented with Essential.

dichromate solution at $4^{\circ} \mathrm{C}$. For use, the potassium dichromate solution was washed out with tap water by repeated centrifugation and the oocysts were estimated by counting in a McMaster chamber using microscopy. The dose of sporulated oocysts was adjusted to cause $10 \%$ mortality in the infected birds and was administered through the feed at $14 \mathrm{~d}$ old. The optimal dose was determined from a preliminary experiment and it was approximately 100,000, 30,000 and 75,000 oocysts/bird for Eimeria acervulina, Eimeria maxima and Eimeria tenella, respectively.

Detection of coccidia: Five birds from each pen were sacrificed by cervical dislocation and gross lesion score was evaluated 7 and $14 \mathrm{~d}$ post-inoculation. The intestinal tract was removed immediately after death and examined macroscopically under a strong light. Lesion scores were evaluated (Johnson and Reid, 1970) and ranged from 0 (no gross lesions) to 4 (most severe gross lesions).

Performance: The broilers and the feed were weighed at $7,14,21,28,35$, and $42 \mathrm{~d}$ of age to evaluate performance, which was measured as the feed intake, weight gain, and feed conversion rate. Broiler mortality was recorded daily to correct the feed:gain per pen and to calculated the livability (\%) of the birds at 21 and $42 \mathrm{~d}$ of age.

Statistics: Pen means were used as the experimental unit for all analyses. The data on the weight gain and feed efficiency were analyzed using an analyses of variance (ANOVA) and linear model procedure of SAS with mean separation by $F$ test $(p<0.05)$. As no animals were challenged until $14 \mathrm{~d}$ of age, the challenged and nonchallenged treatments were analyzed as single treatments for 1.5 and $2.0 \mathrm{~kg} / \mathrm{ton}$. The lesion scores were compared using the non-parametric Kruskal-Wallis test (SAS, 2007). 
Exp. 2, metabolizability and intestinal histology experiment

Animals, experimental design and dietary treatments: A total of 594 one-day-old male (Cobb-500) broilers were obtained from a commercial hatchery. The experimental design included broilers randomly assigned to two treatments. The treatments were comprised of one control diet without Essential inclusion and one diet with inclusion of Essential ( 0 and $1.5 \mathrm{~kg} /$ ton) in the feed; the experimental units were repeated nine times with 33 birds each. The diets were corn and soybean meal based. The starter diet was fed from d 1 to 14 , and contained $21.50 \%$ crude protein (CP) and $2,980 \mathrm{kcal}$ of metabolizable energy $(\mathrm{ME}) / \mathrm{kg}$ on a dry matter (DM) basis. The growth diet was fed from d 15 to 28 , and contained $20.00 \% \mathrm{CP}$ and $3,050 \mathrm{kcal}$ of $\mathrm{ME} / \mathrm{kg}$. The finisher diet which was fed from d 29 to 42 had $18.80 \% \mathrm{CP}$ and $3,125 \mathrm{kcal} / \mathrm{kg} \mathrm{ME}$ (Table 2). All other nutrients met or exceeded Brazilian nutrient requirements for broiler chickens (Rostagno et al., 2005).

Performance: The broilers and the feed were weighed at 14, 28 and $42 \mathrm{~d}$ of age to evaluate performance, which was measured as the feed intake, weight gain, and feed conversion rate. Broiler mortality was recorded daily to correct the feed:gain per pen.

Intestinal morphometric indices: The morphometric analyzes were performed following the recommendations of Luna (1968). Samples with approximately $2 \mathrm{~cm}$ of each intestinal segment (duodenum, jejunum and ileum) were taken from two chickens of each experimental unit at $\mathrm{d} 7$, 14, 21 and 28. The samples were washed in $0.9 \%$ saline solution to remove the contents, fixed in a $10 \%$ formaldehyde solution, dehydrated in increasing concentrations of alcohol, cleared in xylene and paraffin embedded to obtain the histological cross-cuts. The cuts were stained with Hematoxilin-Eosin method and read under the microscope, 60 measurements (30 measurements for the height of the villus and 30 for the crypt depth) were done for each segment. The morphometric indices evaluated were villus height from the tip of the villus to the crypt, crypt depth from the base of the villi to the submucosa, and the villus height to crypt depth ratio.

Digestibility: At $21 \mathrm{~d}$ of age 126 broilers were transferred to metabolic cages. The experimental design included broilers assigned to seven replicates and nine birds per experimental unit according to the treatment that they were receiving (supplementation or not of Essential). The experimental period included five days of adaptation and five days of total excreta collection. At the end of experimental period, based on the results of the analyzes of gross energy, DM and nitrogen in the excreta and feed were calculated the $\mathrm{AME}$ and $\mathrm{AME}_{\mathrm{n}}$, according to the equations proposed by Matterson et al. (1965). The coefficient of protein and ether extract digestibility was calculated by the difference between protein/ether extract in the diet and the amounts in the feces, according to Sakomura and Rostagno (2007).

Statistics: All parameters were analyzed with an ANOVA as a completely randomized design using the general linear model procedure of SAS with mean separation by F test (SAS, 2007).

\section{RESULTS AND DISCUSSION}

\section{Coccidiosis inoculation experiment}

Pre challenge period: Weight gain was higher $(\mathrm{p}<0.05)$ and feed conversion rate was also better $(p<0.05)$ during the pre-challenge period ( 1 to $14 \mathrm{~d}$ of age) for the birds supplemented with Essential (Table 3). The level of the Essential supplementation did not affect the weight gain and feed efficiency. Essential oils previously have shown an improving effect on feed conversion rate (Tedesco, 2001; Isabel and Santos, 2009).

Even when considering that Essential might be affecting digestive or metabolic enzymes that could improve nutrient absorption or utilization, the differences between the control treatment and the birds supplemented with Essential were unexpectedly large. However, the control diet did not contain any growth promoter or coccidiostat and the birds might have been exposed to a strong bacterial challenge. Ricinoleic acid has been shown to have antibacterial properties against gram positive bacteria (Novak et al., 1961) and the components of CNSL have also been shown to inhibit methicillin resistant Staphylococcus aureus (Kubo et al., 2003). Therefore, although the differences between the control treatment and the treatments supplemented with Essential were larger than expected, it was not surprising to find improved weight gain and feed conversion rate in the treatments supplemented with Essential.

Post challenge period: The weight gain from 14 to $21 \mathrm{~d}$ of age was decreased with the coccidiosis challenge $(\mathrm{p}<0.05)$ and ameliorated $(\mathrm{p}<0.05)$ with the Essential supplementation (Table 3). Although the coccidiosis challenge decreased the weight gain from 21 to 28 and from 28 to 35 d, Essential supplementation did not improve ( $p>$ $0.05)$ the weight gain during these periods. No difference ( $>0.05$ ) in weight gain was seen from 35 to $42 \mathrm{~d}$. The control group showed a better $(\mathrm{p}<0.05)$ feed conversion rate than some of the treatments supplemented with Essential from 28 to 35 and from 35 to 42 days (Table 3), which may be due to compensatory growth. It can also be hypothesized that the higher mortality in the control group removed the weaker animals while the more efficient animals survived (Table 4).

Live weights were consistently higher $(\mathrm{p}<0.05)$ for the treatments supplemented with Essential (Figure 1) from 7 to $42 \mathrm{~d}$ of age. The coccidiosis challenge significantly 
Table 3. Weight gain and feed conversion rate for the birds with and without Essential supplementation at pre-coccidial challenge (1 to 14 days) and weight gain and feed convertion rate for the birds with and without Essential supplementation after the coccidiosis challenge (Exp. 1)

\begin{tabular}{lcc}
\hline \multirow{2}{*}{ Treatments } & \multicolumn{2}{c}{ Pre-coccidial challenge } \\
\cline { 2 - 3 } & Weight gain & Feed conversion rate \\
\hline Control & $234.73^{\mathrm{a}}$ & $1.389^{\mathrm{a}}$ \\
Essential $(1.5 \mathrm{~kg} /$ ton $)$ & $327.27^{\mathrm{b}}$ & $1.232^{\mathrm{b}}$ \\
Essential $(2.0 \mathrm{~kg} /$ ton $)$ & $329.68^{\mathrm{b}}$ & $1.235^{\mathrm{b}}$ \\
SEM & 8.55 & 0.035 \\
$\mathrm{p}$ value & 0.0001 & 0.0001 \\
\hline
\end{tabular}

\begin{tabular}{|c|c|c|c|c|c|}
\hline & \multicolumn{5}{|c|}{ After coccidiosis challenge } \\
\hline & \multirow{2}{*}{ Challenge } & \multicolumn{4}{|c|}{ Weight gain $(\mathrm{g})$} \\
\hline & & 14 to $21 \mathrm{~d}$ & 21 to $28 \mathrm{~d}$ & 28 to $35 \mathrm{~d}$ & 35 to $42 \mathrm{~d}$ \\
\hline \multicolumn{6}{|c|}{ Essential (kg/ton) } \\
\hline 0 & + & $203.2^{\mathrm{a}}$ & $457.0^{\mathrm{a}}$ & $866.3^{\mathrm{a}}$ & 1013.6 \\
\hline 1.5 & - & $417.7^{\mathrm{b}}$ & $553.8^{\mathrm{b}}$ & $990.5^{\mathrm{b}}$ & 859.6 \\
\hline 1.5 & + & $310.5^{\mathrm{c}}$ & $496.3^{\mathrm{a}}$ & $960.7^{\mathrm{a}}$ & 941.1 \\
\hline 2 & - & $419.7^{\mathrm{b}}$ & $552.6^{\mathrm{b}}$ & $992.5^{\mathrm{b}}$ & 997.3 \\
\hline 2 & + & $305.6^{\mathrm{c}}$ & $486.2^{\mathrm{a}}$ & $978.4^{\mathrm{a}}$ & 910.8 \\
\hline SEM & & 15.5 & 8.3 & 11.7 & 25.5 \\
\hline \multirow[t]{3}{*}{$\mathrm{p}$ value } & & 0.0001 & 0.0001 & 0.0003 & 0.31 \\
\hline & Challenge & \multicolumn{4}{|c|}{ Feed conversion rate $(\mathrm{g})$} \\
\hline & Chancinge & 14 to $21 \mathrm{~d}$ & 21 to $28 \mathrm{~d}$ & 28 to $35 \mathrm{~d}$ & 35 to $42 \mathrm{~d}$ \\
\hline \multicolumn{6}{|c|}{ Essential (kg/ton) } \\
\hline 0 & + & $1.762^{\mathrm{a}}$ & 1.494 & $1.625^{\mathrm{a}}$ & $1.603^{\mathrm{a}}$ \\
\hline 1.5 & - & $1.365^{\mathrm{b}}$ & 1.551 & $1.721^{\mathrm{ab}}$ & $1.908^{\mathrm{b}}$ \\
\hline 1.5 & + & $1.611^{\mathrm{c}}$ & 1.640 & $1.736^{\mathrm{b}}$ & $1.724^{\mathrm{ab}}$ \\
\hline 2 & - & $1.378^{\mathrm{b}}$ & 1.574 & $1.733^{\mathrm{b}}$ & $1.779^{\mathrm{ab}}$ \\
\hline 2 & + & $1.605^{\mathrm{c}}$ & 1.685 & $1.751^{\mathrm{b}}$ & $1.830^{\mathrm{ab}}$ \\
\hline SEM & & 0.033 & 0.015 & 0.013 & 0.035 \\
\hline$p$ value & & 0.0001 & 0.12 & 0.01 & 0.048 \\
\hline
\end{tabular}

SEM, standard error of the mean.

Values are means of 10 replicate pens per treatment, with each pen having 50 birds at $1 \mathrm{~d}$ of age.

${ }^{\text {abc }}$ Means with a different superscript letter within a column are significantly different $(\mathrm{p}<0.05)$.

decreased $(\mathrm{p}<0.05)$ the weights from 14 to $28 \mathrm{~d}$ in the treatments supplemented with Essential. However, there were no differences in the weights from 28 to $42 \mathrm{~d}$ of age.

Livability at $21 \mathrm{~d}$ of age $(7 \mathrm{~d}$ post-challenge) was approximately $10 \%$ lower for the control group $(\mathrm{p}<0.05)$ when compared to the groups that received diets supplemented with Essential (Table 4). Dosage of Essential and the coccidiosis challenge did not affect $(p>0.05)$ the livability among the treatments supplemented with Essential.

The intestinal lesion score $7 \mathrm{~d}$ post challenge in the anterior intestine and cecum was lower $(p<0.05)$ for the birds that received the treatments supplemented with Essential, with both dosages being equally effective (Table 4). No differences were observed between treatment groups in the median intestine lesion score. The intestinal lesion score $14 \mathrm{~d}$ post challenge was low for all treatments, showing the normal recovery from the infection. There was no difference between treatments groups with respect to recovery from the infection. The higher cecal lesion score that was observed in the control group correlates well with the higher mortality in the same group, as Eimeria tenella is usually considered the most pathogenic of the coccidian parasites and the mortality due to coccidiosis is usually associated with this species (McDougald, 1998). The lower lesion score from the anterior intestine that is attributed to Eimeria acervulina would therefore correlate with the lower $(\mathrm{p}<0.05)$ weight gains and the increased feed conversion rate observed in the control group $7 \mathrm{~d}$ post-challenge. Infections with Eimeria acervulina and Eimeria maxima are usually associated with decreases in feed efficiency and in the growth rate when the birds are affected during the third week of age (Voeten, 1985). The positive effects of Essential on the intestine lesion score of inoculated birds could be attributed to either a direct anticoccidial effect or to an antioxidant effect on the host intestinal cells that 
Table 4. Livability (\%) of the birds at 21 and $42 \mathrm{~d}$ of age and intestinal lesion score of the birds 7 and $14 \mathrm{~d}$ after a coccidiosis challenge (21 and $28 \mathrm{~d}$ of age) with and without Essential supplementation (Exp. 1)

\begin{tabular}{|c|c|c|c|c|c|c|}
\hline \multirow[t]{2}{*}{ Suplementation } & \multirow{2}{*}{\multicolumn{2}{|c|}{ Challenge }} & \multicolumn{4}{|c|}{ Livability (\%) } \\
\hline & & & \multicolumn{2}{|c|}{1 to $21 \mathrm{~d}$} & \multicolumn{2}{|c|}{21 to $42 \mathrm{~d}$} \\
\hline \multicolumn{7}{|l|}{ Essential (kg/ton) } \\
\hline 0 & \multicolumn{2}{|c|}{+} & \multicolumn{2}{|c|}{$87.33^{\mathrm{a}}$} & \multicolumn{2}{|c|}{96.25} \\
\hline 1.5 & \multicolumn{2}{|c|}{ - } & \multicolumn{2}{|c|}{$97.00^{\mathrm{b}}$} & \multicolumn{2}{|c|}{95.83} \\
\hline 1.5 & \multicolumn{2}{|c|}{+} & \multicolumn{2}{|c|}{$97.33^{\mathrm{b}}$} & \multicolumn{2}{|c|}{93.33} \\
\hline 2 & \multicolumn{2}{|c|}{ - } & \multicolumn{2}{|c|}{$98.00^{\mathrm{b}}$} & \multicolumn{2}{|c|}{97.08} \\
\hline 2 & \multicolumn{2}{|c|}{+} & \multicolumn{2}{|c|}{$97.33^{\mathrm{b}}$} & \multicolumn{2}{|c|}{96.25} \\
\hline SEM & & & \multicolumn{2}{|c|}{2.24} & \multicolumn{2}{|c|}{3.40} \\
\hline \multirow[t]{4}{*}{$\mathrm{p}$ value } & & & \multicolumn{2}{|c|}{0.0001} & \multicolumn{2}{|c|}{0.35} \\
\hline & \multicolumn{6}{|c|}{ Intestinal lesion score } \\
\hline & \multicolumn{3}{|c|}{21 days } & \multicolumn{3}{|c|}{28 days } \\
\hline & Anterior & Median & Cecum & Anterior & Median & Cecum \\
\hline \multicolumn{7}{|l|}{ Essential (kg/ton) } \\
\hline 0 & $2.60^{\mathrm{a}}$ & 0.90 & $2.30^{\mathrm{a}}$ & 0.13 & 0.40 & 0.53 \\
\hline 1.5 & $1.63^{\mathrm{b}}$ & 0.97 & $1.20^{\mathrm{b}}$ & 0.06 & 0.27 & 0.07 \\
\hline 2 & $1.87^{\mathrm{b}}$ & 0.70 & $1.30^{\mathrm{b}}$ & 0.10 & 0.33 & 0.13 \\
\hline SEM & 0.16 & 0.16 & 0.17 & 0.06 & 0.12 & 0.09 \\
\hline $\mathrm{p}$ value & 0.003 & 0.67 & 0.0008 & 0.93 & 0.94 & 0.09 \\
\hline
\end{tabular}

SEM, standard error of the mean.

Values for livability are means of 10 replicate pens per treatment.

Values for intestinal lesion score are means of 10 replicates ( 5 birds per replicate pen).

${ }^{\mathrm{ab}}$ Means with a different superscript letter within a column are significantly different $(\mathrm{p}<0.05)$.

protected them against the challenge. However, with the data collected in this study it is impossible to determine if either one or both effects contributed to the improved response to the challenge.
Although no differences were observed in the lesion score from the median intestine, lesion scoring does not fully reflect the degree of disease severity in induced infections. Furthermore, high lesion scores are associated

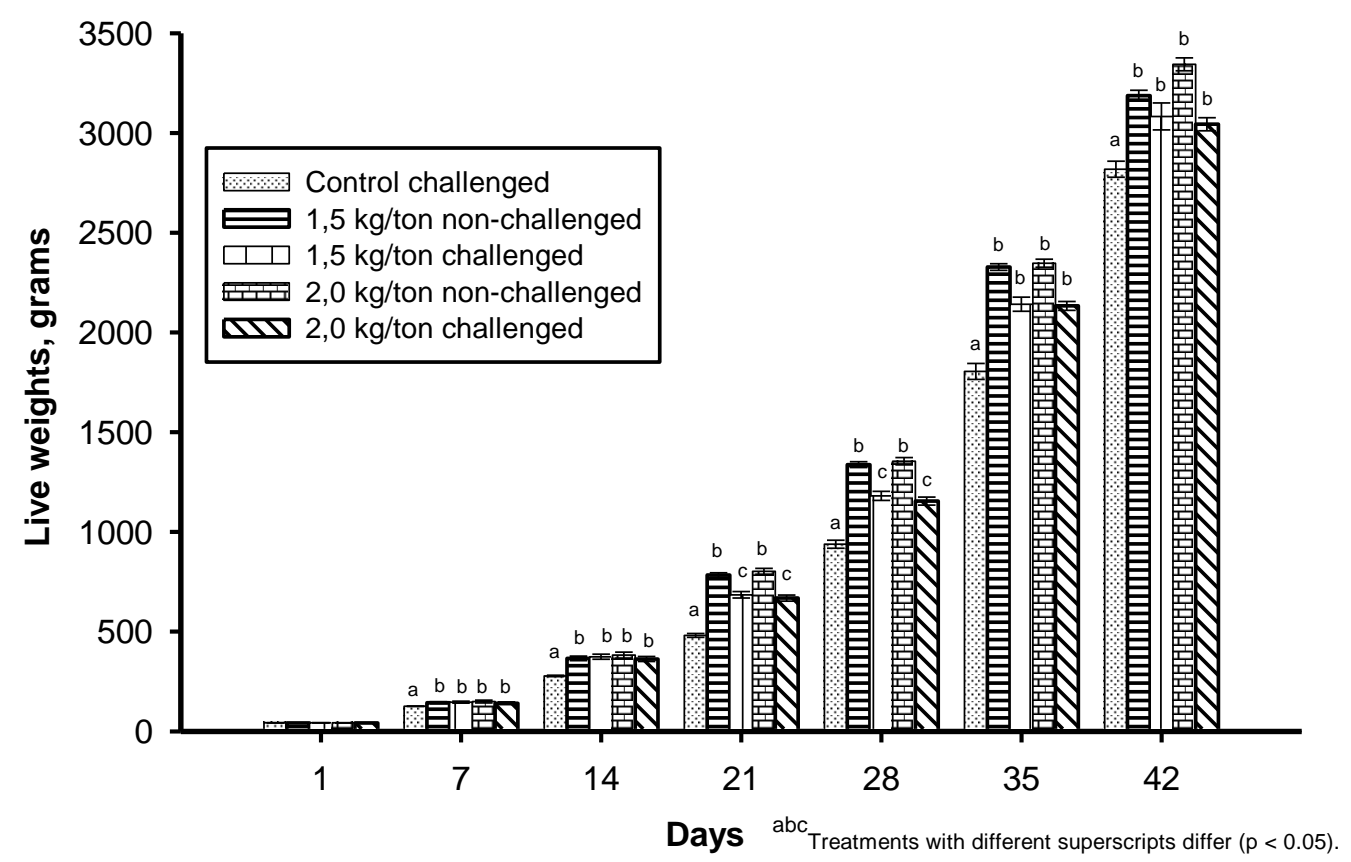

Figure 1. Live weights of treatments with and without Essential supplementation during the whole experiment (the birds were challenged with coccidiosis at 14 days of age). Values are means of 10 replicate pens per treatment, with each pen having 50 birds at $1 \mathrm{~d}$ of age. 
with small changes in weight gain in medicated birds when compared with non-medicated birds (Conway et al., 1990). Unfortunately, it was not possible to separate the effect of the three species of coccidian on the feed efficiencies and the growth rates. However, infections with Eimeria maxima usually have a dramatic effect on the feed efficiencies. As such dramatic effects were not seen in the birds supplemented with Essential it is possible that such supplementation may have ameliorated the effects of the infection as is observed with coccidiostats such as salinomycin (Voeten, 1985).

Metabolizability and intestinal histology experiment: There were no differences $(\mathrm{p}>0.05)$ in live weight, weight gain or feed conversion during the 42-d experimental period (Table 5). These results are similar to those reported by López et al. (2012). According to these authors, no improvement in performance parameters could be explained by the lack of challenge in the experimental conditions, which included well-nourished animals and a disinfected environment. Therefore, the difference between the performance parameters observed in Exp. 1 and 2 could similarly be explained. Probably, in the Exp. 2 the environmental conditions were better than in the Exp. 1, so the Essential did not provide the same benefits. Therefore, an extensive knowledge of the animal housing environment is essential for accurate interpretation of results (Bedford, 2000).

However, $\mathrm{AME}$ and $\mathrm{AME}_{\mathrm{n}}$ values for the diet supplemented with Essential were approximately $4 \%$ higher $(\mathrm{p}<0.05)$ than that of the control diet (Table 5). These results are in accordance with those reported by Bess et al. (2012). The authors showed that the supplementation of the same mixture of functional oils allowed not only for an improvement in the performance of birds but also for a decrease in ME of $100 \mathrm{kcal} / \mathrm{kg}$ without a negative effect on performance, demonstrating a more efficient use of nutrients. No differences ( $p>0.05$ ) were seen in coefficients of digestibility of protein or ether extract. Additionally, Jang et al. (2004) observed an increased trypsin and pancreatic amylase activity in broilers fed diets containing a blend of commercial essential oils combined with lactic acid.

There were no differences in villus height and crypt depth between treatments other than a higher $(\mathrm{p}<0.05)$ villus height in the jejunum for the birds supplemented with Essential on d 14 (Table 6). However, villus height to crypt depth ratios for the birds supplemented with Essential were larger $(\mathrm{p}<0.05)$ in the jejunum on $\mathrm{d} 7$ and in the jejunum and ileum on d 14 (Table 6). Increasing ileum and jejunum villus height to crypt depth ratio in birds supplemented with Essential may suggest an increased surface area and these changes are capable of providing a beneficial effect on the utilization of nutrients (Caspary, 1992). A greater absorption of nutrients could explain, at least, part of the increase in $\mathrm{AME}$ and $\mathrm{AME}_{\mathrm{n}}$ seen in diets supplemented with Essential. It has been well document that antimicrobial agents are capable of reducing the intestinal microbial load, resulting in a decrease of toxins that are associated with negative changes in intestinal morphology (Xu et al., 2003).

In conclusion, supplementation of Essential in birds challenged with coccidiosis improved the livability and

Table 5. Live weight, weight gain, feed conversion rate for control and bird supplemented with Essential and $A M E$, $A M E_{n}$ and coefficients of protein and ether extract digestibility for the control and Essential supplemented diets (Exp. 2)

\begin{tabular}{|c|c|c|c|c|c|}
\hline & Days & Control & Essential & SEM & $\mathrm{p}$ value \\
\hline \multirow[t]{3}{*}{ Live weight } & 14 & 381.6 & 400 & 8.2 & 0.28 \\
\hline & 28 & $1,247.3$ & $1,255.8$ & 12.3 & 0.75 \\
\hline & 42 & $2,644.1$ & $2,682.2$ & 24.6 & 0.46 \\
\hline \multirow[t]{4}{*}{ Weight gain } & 1 to 14 & 337.8 & 356 & 8.2 & 0.29 \\
\hline & 15 to 28 & 865.7 & 855.845 & 12.8 & 0.72 \\
\hline & 29 to 42 & $1,396.9$ & $1,426.4$ & 20.9 & 0.51 \\
\hline & 1 to 42 & $2,644.2$ & $2,682.2$ & 24.6 & 0.46 \\
\hline \multirow[t]{4}{*}{ Feed conversion } & 1 to 14 & 1.542 & 1.5 & 0.019 & 0.31 \\
\hline & 15 to 28 & 1.751 & 1.756 & 0.019 & 0.89 \\
\hline & 29 to 42 & 1.911 & 1.851 & 0.021 & 0.16 \\
\hline & 1 to 42 & 1.806 & 1.772 & 0.01 & 0.08 \\
\hline AME (kcal/kg) & & $2,777^{\mathrm{a}}$ & $2,881^{\mathrm{b}}$ & 41 & 0.003 \\
\hline $\mathrm{AME}_{\mathrm{n}}(\mathrm{kcal} / \mathrm{kg})$ & & $2,449^{\mathrm{a}}$ & $2,568^{\mathrm{b}}$ & 41 & 0.001 \\
\hline $\mathrm{CDP}(\%)$ & & 63.59 & 63.69 & 2 & 0.93 \\
\hline CDEE $(\%)$ & & 63.91 & 56.14 & 5 & 0.15 \\
\hline
\end{tabular}

AME, apparent metabolizable energy; $\mathrm{AME}_{\mathrm{n}}$, nitrogen-corrected apparent metabolizable energy; SEM, standard error of the mean; CDP, coefficient of protein digestibility; CDEE, coefficient of ether extract digestibility.

Values for performance parameters are means of 9 replicate pens per treatment, with each pen having 33 birds at $1 \mathrm{~d}$ of age.

Values for digestibility parameters are means of 7 replicate pens per treatment, with each pen having 9 birds at $21 \mathrm{~d}$ of age.

${ }^{\mathrm{ab}}$ Means with a different superscript letter within a row are significantly different $(\mathrm{p}<0.001)$. 
Table 6. Villus height, crypt depth and villus to crypt ratio in the duodenum, jejunum and ileum in chickens fed diets with and without Essential (Exp. 2)

\begin{tabular}{|c|c|c|c|c|c|c|c|c|c|}
\hline \multirow{2}{*}{ Treatments } & \multicolumn{3}{|c|}{ Villus height $(\mu \mathrm{m})$} & \multicolumn{3}{|c|}{ Crypt depth $(\mu \mathrm{m})$} & \multicolumn{3}{|c|}{ Villus/crypt rate } \\
\hline & Duodenum & Jejunum & Ileum & Duodenum & Jejunum & Ileum & Duodenum & Jejunum & Ileum \\
\hline \multicolumn{10}{|l|}{7 days } \\
\hline Control & $1,167.29$ & 586.48 & 380.06 & 153.07 & 110.92 & 84.58 & 7.88 & $5.24^{\mathrm{a}}$ & 4.54 \\
\hline Essential & $1,142.58$ & 639.80 & 364.15 & 142.69 & 115.73 & 84.26 & 7.71 & $5.74^{\mathrm{b}}$ & 4.53 \\
\hline SEM & 75.07 & 77.36 & 48.71 & 218.42 & 128.37 & 71.27 & 0.78 & 0.33 & 0.49 \\
\hline $\mathrm{p}$ value & 0.46 & 0.27 & 0.48 & 0.35 & 0.54 & 0.95 & 0.76 & 0.03 & 0.99 \\
\hline \multicolumn{10}{|l|}{14 days } \\
\hline Control & $1,254.32$ & $553.96^{\mathrm{a}}$ & 449.28 & 177.43 & 123.41 & 104.5 & 7.36 & $4.75^{\mathrm{a}}$ & $4.52^{\mathrm{a}}$ \\
\hline Essential & $1,328.25$ & $715.40^{\mathrm{b}}$ & 493.04 & 148.72 & 130.11 & 92.34 & 7.21 & $6.45^{\mathrm{b}}$ & $5.68^{\mathrm{b}}$ \\
\hline SEM & 135.20 & 115.19 & 68.65 & 263.87 & 160.57 & 96.50 & 0.67 & 0.04 & 0.74 \\
\hline $\mathrm{p}$ value & 0.19 & 0.002 & 0.28 & 0.16 & 0.53 & 0.12 & 0.79 & 0.0004 & 0.03 \\
\hline \multicolumn{10}{|l|}{21 days } \\
\hline Control & $1,516.2$ & 767.28 & 514.16 & 142.76 & 117.99 & 106.98 & 10.43 & 6.65 & 4.90 \\
\hline Essential & $1,541.63$ & 866.08 & 545.09 & 164.21 & 111.08 & 98.4 & 9.49 & 7.30 & 5.62 \\
\hline SEM & 242.79 & 109.84 & 70.65 & 234.43 & 131.06 & 105.27 & 2.47 & 0.98 & 0.28 \\
\hline $\mathrm{p}$ value & 0.77 & 0.15 & 0.36 & 0.10 & 0.38 & 0.25 & 0.40 & 0.29 & 0.26 \\
\hline \multicolumn{10}{|l|}{28 days } \\
\hline Control & $1,706.76$ & 892.17 & 699.27 & 165.92 & 127.98 & 134.68 & 10.39 & 7.29 & 5.17 \\
\hline Essential & $1,630.52$ & 810.06 & 581.38 & 161.9 & 131.62 & 112.2 & 9.06 & 6.15 & 4.87 \\
\hline SEM & 237.28 & 171.67 & 68.77 & 268.62 & 168.45 & 151.11 & 0.64 & 1.37 & 0.36 \\
\hline $\mathrm{p}$ value & 0.33 & 0.27 & 0.29 & 0.73 & 0.72 & 0.12 & 0.15 & 0.11 & 0.33 \\
\hline
\end{tabular}

SEM, standard error of the mean.

Values are means of 9 replicates (2 birds per replicate pen).

${ }^{\mathrm{ab}}$ Means with a different superscript letter within a column are significantly different $(\mathrm{p}<0.05)$.

decreased the intestinal lesion score in the anterior intestine and cecum at $21 \mathrm{~d}$ of age regardless of the dosage. Weight gain and feed efficiency were improved for the chickens supplemented with Essential before the coccidiosis challenge and during the first $7 \mathrm{~d}$ post infection. Improvements in $\mathrm{AME}$ and $\mathrm{AME}_{\mathrm{n}}$ seen in the metabolizability trial could explain, at least in part, the improved weights and feed efficiencies for the birds supplemented with Essential.

\section{REFERENCES}

Bedford, M. 2000. Removal of antibiotic growth promoters from poultry diets: Implications and strategies to minimise subsequent problems. World's Poult. Sci. J. 56:347-365.

Bess, F., A. Favero, S. L. Vieira, and J. Torrent. 2012. The effects of functional oils on broiler diets of varying energy levels. J. Appl. Poult. Res. 21:567-578.

Caspary, W. F. 1992. Physiology and pathophysiology of intestinal absorption. Am. J. Clin. Nutr. 55:299S-308S.

Conway, D. P., M. E. McKenzie, and A. D. Dayton. 1990. Relationship of coccidial lesion scores and weight gain in infections of Eimeria acervulina, E. maxima, and E. tenella in broilers. Avian Pathol. 19:489-496.

Isabel, B. and Y. Santos. 2009. Effects of dietary organic acids and essential oils on growth performance and carcass characteristics of broiler chickens. J. Appl. Poult. Res. 18:472-
476.

Itokawa, H., N. Totsuka, K. Nakahara, M. Maezuru, K. Takeya, and M. Kondo. 1989. A quantitative structure-activity relationship for antitumor activity of long-chain phenols from Ginko biloba L. Chem. Pharm. Bull. 37:1619-1621.

Jang, I. S., Y. H. Ko, H. Y. Yang, J. S. Ha, J. Y. Kim, S. Y. Kang, D. H. Yool, D. S. Naml, D. H. Kim, and C. Y. Lee. 2004. Influence of essential oil components on growth performance and functional activity of the pancreas and small intestine in broiler chickens. Asian Australas. J. Anim. Sci. 17:394-400.

Johnson, J. and W. M. Reid. 1970. Anticoccidial drugs: lesion scoring techniques in battery and floor-pen experiments with chickens. Exp. Parasitol. 28:30-36.

Kubo, I., S. Komatsu, and M. Ochi. 1986. Molluscicides from the cashew Anacardium occidentale and their large-scale isolation. J. Agric. Food Chem. 34:970-973.

Kubo, I., K. Nihei, and K. Tsujimoto. 2003. Antibacterial action of anacardic acids against Methicillin Resistant Staphylococcus aureus (MRSA). J. Agric. Food Chem. 51:7624-7628.

López, C. A. A., K. R. S. Lima, M. C. Manno, F. B. Tavares, D. L. Fernandes Neto, M. L. C. Jesus, M. A. O. Viana, and L. A. B. Fonseca. 2012. Effects of cashew nut shell liquid (CNSL) on the performance of broiler chickens. Arq. Bras. Med. Vet. Zootec. 64:1027-1035.

Luna, G. C. 1968. Manual of Histologic Staining Methods of the Armed Forces Institut of pathology. 3.ed. Mc Graw-Hill, New York, USA. p. 285.

Maenz, D. D. and G. W. Forsyth. 1982. Ricinoleate and 
deoxycholate are calcium ionophores in jejunal brush border vesicles. J. Membr. Biol. 70:125-133.

Matterson, L. D., L. M. Potter, N. W. Stutz, and E. P. Singsen. 1965. The metabolizable energy of feed ingredients for chickens. Res. Rep. 7:3-11.

McDougald, L. R. 1998. Intestinal protozoa important to poultry. Poult. Sci. 77:1156-1158.

Muroi, H. and I. Kubo. 1996. Antibacterial activity of anacardic acid and totarol, alone and in combination with methicillin, against methicillin resistant Staphylococcus aureus. J. Appl. Bacteriol. 80:387-394.

Novak, A. F., G. C. Clark, and H. P. Dupuy. 1961. Antimicrobial activity of some ricinoleic and oleic acid derivatives. J. Am. Oil Chem. Soc. 38:321-324.

Rostagno, H. S, L. F. T. Albino, J. L. Donzele, P. C. Gomes, R. F. Oliveira, D. C. Lopes, A. S. Ferreira, and L. S. T. Barreto. 2005. Brazilian tables for poultry and swine: Composition of feedstuffs and nutritional requirements. 2 ed. Viçosa, UFV, Brazil.

Sakomura, N. K. and H. S. Rostagno. 2007. Research methods in nutrition of monogastrics. Jaboticabal: FUNEP, p. 283.
SAS Institute. 2007. SAS User's Guide: Version 7.0 edn. SAS Inst. Inc., Cary, NC, USA.

Tedesco, D. 2001. The potentially of herbs and plant extracts as feed additives in livestock production. Zootec. Nutr. Anim. 27:111-133.

Toyomizu, M., K. Okamoto, T. Ishibashi, Z. Chen, and T. Nakatsu. 1999. Uncoupling effect of anacardic acids from cashew nut shell oil on oxidative phosphorylation of rat liver mitochondria. Life Sci. 66:229-234.

Vieira, C., S. Fetzer, S. K. Sauer, S. Evangelista, B. Averbeck, M. Kress, P. W. Reeh, R. Cirillo, A. Lippi, C. A. Maggi, and S. Manzini. 2001. Pro- and anti-inflammatory actions of ricinoleic acid: similarities and differences with capsaicin. Naunyn Schmiedebergs Arch. Pharmacol. 364:87-95.

Voeten, A. C. 1985. Recent developments in the field of anticoccidial agents for poultry. In: Recent Advances in Animal Nutrition (Eds. W. Haresign and D. J. A. Cole). Butterworth \& Co., London. p. 292-303.

Xu, Z. R., C. H. Hu, M. S. Xia, X. A. Zhan, and M. Q. Wang. 2003. Effects of dietary fructooligosaccharide on digestive enzyme activities, intestinal microflora and morphology of male broilers. Poult. Sci. 82:1030-1036. 